\title{
MEMÓRIA DE MARGOT
}

\author{
Roberto Akira Goto ${ }^{1}$ \\ Docente aposentado de Filosofia da Educação \\ Departamento de Filosofia e História da Educação \\ Faculdade Educação, Universidade Estadual de Campinas, Brasil \\ goto@unicamp.br
}

Como os assentamentos burocrático-administrativos permitem presumir, é provável que tenha começado a lecionar no colégio no segundo semestre de 1963. No Livro de Registro de Contratos de Professores, o seu é o de número 39, assim redigido: "Nos termos do artigo 14, n II, da lei $\mathrm{n}^{\circ} 3.345$, de 17-1-56, combinado com o artigo $1^{\circ}$ da lei 7.817, de 5-2-1963, e após cumpridas as formalidades dos artigos $6^{\circ}$ (n. XIV) e 11 (n. V), da referida primeira lei acima, fica contratada a professora d. MARgot PROEnÇA, para ministrar aulas de Filosofia, durante o período de $1^{\circ}$ de agosto de 1963 a 28 de fevereiro de 1964, condicionada a permanência nesse período à aprovação da Comissão de Acumulação de Cargos, obrigando-se ao cumprimento, inclusive, de todas as obrigações atinentes à função, determinadas pelas leis, regulamentos e regimentos vigentes. / Campinas, $1^{\circ}$ de agosto de 1963."

A lei 7.817, segundo sua ementa, estendia "ao Colégio Estadual Culto à Ciência, de Campinas, o regime de autonomia didática e administrativa, estabelecido para o Colégio Estadual de São Paulo pela lei n. 3.345”. A autonomia implicava a existência de um corpo docente composto por três categorias de professores - catedráticos, contratados e interinos - e de uma congregação, constituída pelos catedráticos (cujos cargos, vitalícios e inamovíveis, eram providos por concursos de títulos e provas). A congregação indicava dentre seus membros o diretor e o vice-diretor, que eram então nomeados pelo governo estadual para mandatos de dois anos, "permitida a recondução", conforme estabelecia o art. $4^{\circ}$ da lei de 1956. Ao diretor atribuía-se o poder de "indicar ao Governo, ouvida a Congregação, nomes de professores para contrato e regência interina" (é o que dispunha o art. $6^{\circ}$, inciso XIV), ao passo que cabia à congregação, segundo o

\footnotetext{
${ }^{1}$ Foi aluno do Colégio Estadual "Culto à Ciência" em 1970 e 1971, e um de seus professores efetivos de Filosofia entre 1989 e 2004.
}

Rev. Iberoam. Patrim. Histórico-Educativo, Campinas (SP), v. 7, p. 1-5, e021005, 2021. 
inciso V do art. 11, “aprovar a indicação feita pelo Diretor dos nomes de professores para contrato e regência interina".

Obteve ela a aprovação da Comissão de Acumulação de Cargos? (Seu contrato é o único que faz menção a essa condição; tal comissão, aliás, não consta nas leis citadas.) Que cargos estaria acumulando na época? Em que faculdade ou universidade se formara? Questões para quem se interesse e se disponha a pesquisar sua passagem pela famosa escola autônoma, como capítulo da história do ensino de Filosofia em Campinas. De toda a forma, em 1970 continuava por lá. (Em algum momento, nesse período, chegou a prestar concurso para obter a cátedra?) E se, como consta, estava então com 37 anos, teria iniciado a carreira como docente do estabelecimento aos 30 anos de idade.

Como vestígio dessa passagem remanescem, na biblioteca do colégio, exemplares do livro de Manuel Garcia Morente, Fundamentos de Filosofia - compilação, a partir de notas taquigráficas tomadas por alunos, das "lições preliminares" que o autor espanhol (1886-1942) ministrou na Universidade de Tucumán, na Argentina, em 1937 e 1938. Logo nas primeiras aulas, com o volume aberto sobre a carteira, a professora ordenou uma correção - a substituição do i minúsculo pelo maiúsculo na grafia das Ideias platônicas. Sua relação com o livro didático não seria de dependência, muito menos de subordinação; frequentemente iria adiante de seu conteúdo, às vezes ao seu lado, mas sempre comentando-o, enriquecendo-o. Mais fiel ao espírito que à letra do texto, deu vida à proposta do autor: a de propiciar a vivência da Filosofia empreendendo "umas viagens de exploração dentro do continente filosófico" - e é possível que, para um ou outro dos jovens de 16 anos que constituíam o grosso dos matriculados na primeira série do curso colegial (a única das três em que a disciplina era oferecida), a Filosofia tenha mesmo assumido uma dimensão continental, mais expressiva e impressiva que as paisagens e os contornos dos demais componentes curriculares (Português, Estudos Sociais, Matemática, Ciências Físicas e Biológicas, Inglês, Desenho, Educação Moral e Cívica).

Pode ser que, 51 anos depois, a memória do agora velho, lucilando e vacilando, ainda retenha algo da luminosidade vívida de suas aulas expositivas, que passeavam dos pré-socráticos a Aristóteles, de Descartes a Kant, contemplando tanto a informação histórica (outros passeios, como os do Liceu, peripatéticos, e os de Königsberg, metodicamente pontuais) quanto a argumentação racional e/ou a intuição genial (a do motor imóvel, a do cogito, a das categorias $a$ 
priori). Algo, também, dos debates, que dividiam a classe em dois ou mais grupos, empenhados e embrenhados na sustentação e na defesa de pontos de vista acerca de um problema ou da interpretação de uma sentença, desenhada provocativamente na lousa. Se, além disso, guardou algo das provas (oficialmente: sabatinas) da época, poderá retomar e renovar a percepção de como a professora procurava promover nos alunos aquela vivência filosófica.

Para o $1^{\circ}$ Colegial F (a classe em que se achava inscrito então o jovem que o velho foi), a primeira sabatina consistiu no desafio de debruçar-se reflexivamente sobre a pergunta: "A Filosofia deve seu valor às questões que ela coloca ou às respostas que ela dá?” Em outras avaliações, no decorrer daqueles três primeiros bimestres de 1970, ela propôs e instigou:

- "Comente esta frase de Paul Valéry: 'Considero filósofo todo homem - qualquer que seja seu grau de cultura - que tente, de vez em quando, obter uma visão de conjunto, uma visão ordenada, de tudo que ele sabe e, sobretudo, daquilo que ele sabe por experiência direta, interior e exterior.' Observe os seguintes pontos: 1) Este homem construiria um sistema de tipo metafísico ou filosófico (visão de conjunto, ordenada...)? 2) Que método emprega, se parte de uma experiência direta, interior e exterior? (Exemplos conhecidos para comparação.) 3) Faça uma conclusão que relacione toda a frase."

- "Faça uma comparação entre um filósofo, um cientista e um artista abordando os seguintes pontos: 1) Campo de atuação; 2) Métodos ou técnicas empregados; 3) Que personalidade eles deveriam ter, levando-se em consideração os itens 1 e 2.”

- “Comente a frase: 'Há cegos, mudos e tontos que se agitam daqui para lá, multidão de insensatos para quem o ser e o não-ser parecem ora o mesmo, ora coisas diversas, e para quem os caminhos que levam às coisas estão em direções opostas."

Base e pano de fundo da "matéria para prova", o conteúdo do livro tinha de ser estudado e memorizado, mas fazê-lo era insuficiente para haver-se com as tarefas demandadas pelos enunciados (assinalar Parmênides como autor da frase, por exemplo, de nada valia se a informação não ensejasse uma interpretação consistente do texto e de seu contexto). Tampouco era suficiente a doxa, a mera formulação da opinião; "fundamento" e seus cognatos - "fundamentação", "fundamental", "fundamentalmente" - eram vocábulos frequentes de seu discurso didático. Não diferia, quanto a isso, da maioria dos professores, não poucos dos quais manifestavam abertamente sua aversão ao "achismo". E se não só requisitava como estimulava o trabalho interpretativo, é 
porque, tacitamente ao menos, ia na contracorrente da mania de se tomar o texto como portador de uma "mensagem" - mania que outros docentes faziam questão de ironizar explicitamente.

Sim, era exigente - menos, contudo, no que diz respeito aos parâmetros avaliatórios (diziam que reservava a nota máxima "só para Deus", mas ela própria nunca o disse) do que no que concernia ao seu magistério, à substância de seu ensino. Acontece que não levava o aluno pela mão nas incursões e excursões por territórios filosóficos; cada um devia fazê-lo por si próprio, por sua conta e risco, aventurando-se por veredas e ermos desconhecidos. Ela, por sua vez, arriscava-se num diálogo pertinaz, insistente: a cada resposta que alguém apresentava à questão formulada, objetava com um "por quê?"; a nova resposta motivava outra objeção e outro "por quê?", e assim por diante, até que se pudesse vislumbrar, talvez, que a reflexão e a argumentação são passíveis sempre de ser aprofundadas, que as questões filosóficas não são meramente retóricas, que as respostas e razões podem ser múltiplas, como de fato são, que novos fundamentos podem ser assentados para serem, a seguir, também solapados ou deslocados - tudo em meio à percepção ou sensação de que esse diálogo em sala de aula não era simulação do diálogo infindo da Filosofia, mas um seu fragmento, tão autêntico e instrutivo quanto o todo de que ele é parte.

Essa maiêutica rediviva não se limitava a descortinar o filosofar, mas o praticava com a exuberância de sua floração original. A vivência filosófica que ela propiciou podia equiparar-se, doravante, à experiência dos jovens interpelados e interrogados por Sócrates na ágora ateniense. Também ela ensinava espicaçando e arejando mentes, provocando e colocando à prova o pensar. Tinha por regra - que seguia à risca - nunca expor sua opinião pessoal a respeito dos assuntos debatidos e das questões que eram objeto de sua maiêutica, assim respeitando em cada um a liberdade de dispor de seus pensamentos e sentimentos. Quando, no segundo semestre, pôs-se a traduzir e a ditar trechos de uma obra de Lucien Lévy-Bruhl (1857-1939) - provavelmente La mentalité primitive -, foi nesse contexto em que já se exercitava o pensar por conta própria como gesto tensionado pela escolha e carregado de responsabilidade.

É preciso talvez retroceder um passo: para Diotima ou os pré-socráticos; para o mito - mas, neste caso, o da própria Filosofia. Retrocedendo, vê-se que o continente é antes um mundo, na verdade uma constelação, um universo, todo um conjunto de mundos - de outros modos, até então insuspeitados, de ver, viver, sofrer o real. Um dia, no começo do ano (que jamais lhe será dado terminar), irrompe na sala de aula; sopra uma aragem - o vento do pensamento -, abre-se a 
perspectiva infinita do filosofar, na busca do horizonte da sabedoria inalcançável. É um gesto inaugural - fundador, mítico -, lançado pelo ímpeto do entusiasmo, o "deus dentro" assumindo a forma da humana centelha do espanto filosófico, do logos socrático.

Um dia, a Filosofia, pelas mãos da professora Margot - naquele 1970 que a arrebatou do tempo e ficou seu para sempre.

Recebido em: 08 de março de 2021

Aceito em: 09 de março de 2021 